\title{
Current epidemiology of intracranial abscesses: a prospective 5 year study
}

\author{
Sarala Menon, ${ }^{1}$ Renu Bharadwaj, ${ }^{1}$ Abhay Chowdhary, ${ }^{1}$ D. V. Kaundinya ${ }^{1}$ \\ and D. A. Palande ${ }^{2}$ \\ ${ }^{1}$ Department of Microbiology, Grant Medical College and Sir J. J. Hospital, Mumbai 400008, India \\ ${ }^{2}$ Department of Neurosurgery, Grant Medical College and Sir J. J. Hospital, Mumbai 400008, India
}

Correspondence

Sarala Menon

saralagopalmenon@yahoo.co.in

Received 10 December 2007

Accepted 1 June 2008

\section{INTRODUCTION}

Intracranial abscesses are a serious life-threatening condition, and include brain abscess, subdural empyema and intracranial epidural abscess. A brain abscess is a focal, intracerebral infection that begins as a localized area of cerebritis and develops into a collection of pus surrounded by a well-vascularized capsule (Mathisen \& Johnson, 1997). Subdural empyema is focal collection of pus located between the dura mater and the arachnoid mater, while an intracranial epidural abscess involves a pyogenic process and is characterized by accumulation of pus between the skull and the dura mater (Calfee \& Wispelwey, 1999).

Although rare in developed countries, intracranial abscess is still a significant health-care problem in developing countries. This has been reflected by various studies published in the literature (Kao et al., 2003; Seneviratne et al., 2003; Sinha et al., 2003; Bhand, 2004). Most of the reports from India are from later half of the 20th century (Chandramuki et al., 1980; Ayyagari et al., 1983; Bharadwaj \& Joshi, 1988; Lakshmi et al., 1993; De et al., 2000; Sinha et al., 2003). These reports mainly deal with the bacteriology of brain abscesses. In some, the demography also has been discussed. The aim of this study was to analyse the current epidemiological picture of brain abscesses. The data were then compared with the available literature.

Abbreviations: CHD, congenital heart defect; CSOM, chronic suppurative otitis media; ZN, Ziehl-Neelsen.

\section{METHODS}

Patients and samples A prospective study of patients with brain abscess operated over a 5 year period (2001-2005) at the neurosurgery centre of Sir J. J. Hospital, Mumbai, India. The Sir J. J. group of hospitals is the largest referral hospital in the western part of the country and is located in Mumbai, the capital city of Maharashtra. Sir J. J. Hospital has more than 30000 inpatient admissions and more than 500000 patients attending the outpatient department every year. The neurosurgery services of this institute have approximately 795 admissions and 586 surgical procedures annually. Brain abscess accounts for approximately 15 of these procedures per year. This study was carried out after obtaining necessary ethical clearance from the institutional ethical committee.

A patient's level of consciousness at the time of admission was graded on a four-point scale as follows: level 1 - alert without neurological deficit, level 2 - drowsy with minor deficits, level 3 - semi-conscious with moderate deficits, level 4 - coma (Yang \& Zhao, 1993). At the time of diagnosis, initial intravenous broad spectrum antibiotics were given, usually for 2 weeks or more, to cover aerobic (Gram-positive and Gram-negative) and anaerobic organisms. Therapy was then tailored according to the sensitivities of organisms isolated from a pus specimen. Intravenous therapy was continued for a minimum of 2 weeks after surgical drainage, usually followed by a minimum of 4 weeks of oral therapy.

Pus from brain abscesses was collected during neurosurgery either by burr hole or by craniotomy. The pus was inoculated onto suitable solid media for aerobes and anaerobes at the bedside whenever possible or inoculated in Robertson's cooked meat medium for anaerobes. A direct smear was made, fixed in methanol for $30 \mathrm{~s}$ and stained by Gram stain for studying the morphology of infective agents. Ziehl-Neelsen (ZN) staining was also performed on all the pus 
specimens. A $\mathrm{KOH}(10 \%)$ preparation of pus specimens was made when fungal filaments were suspected on a Gram stain.

Aerobes Pus specimens were inoculated on blood agar and MacConkey agar, and incubated aerobically at $37^{\circ} \mathrm{C}$ for $24 \mathrm{~h}$. Similarly, pus specimens were also inoculated on chocolate agar at $37{ }^{\circ} \mathrm{C}$ in $5 \% \mathrm{CO}_{2}$ for $48 \mathrm{~h}$. All the isolates obtained were identified by conventional biochemical reactions (Baron et al., 1994) and antibiotic sensitivity was tested by the Kirby-Bauer disc diffusion method (Bauer et al., 1966).

Anaerobes Pus was inoculated on blood agar, neomycin blood agar and bacteroides bile aesculin agar. All the anaerobic culture plates were incubated at $37{ }^{\circ} \mathrm{C}$ for $48 \mathrm{~h}$ to 7 days in a Gas-Pak system (Dynox/Dynamicro). These plates were observed initially after $48 \mathrm{~h}$ growth. Plates with no growth were further incubated for 5 days before giving a final negative report. A single colony of each distinct type was checked for aerotolerance in $\mathrm{CO}_{2}$. Only strict anaerobes were followed further. Preliminary grouping of isolated anaerobes was performed using $1 \mathrm{mg}$ kanamycin, $10 \mu \mathrm{g}$ colistin, $5 \mu \mathrm{g}$ vancomycin and $1 \mathrm{mg}$ sodium polyanethol sulfonate (Becton Dickinson). Identification of anaerobes was further confirmed by carbohydrate fermentation, gelatin liquefaction, bile resistance, indole production and lipase production (Baron et al., 1994).

Seventy pus specimens obtained from brain abscess patients were also subjected to GLC. In five cases, GLC could not be performed as the samples were of insufficient quantity. One millilitre of pus was acidified with $0.1 \mathrm{ml} 50 \%$ aqueous $\mathrm{H}_{2} \mathrm{SO}_{4}$. This acidified sample was used for detection of volatile and non-volatile fatty acids. Volatile fatty acids were ether extracted, while the non-volatile fatty acids were converted to their volatile methyl ester derivatives by a simple chemical treatment with methanol. They were further analysed by GLC using the method of Willis \& Phillips (1988). GLC was evaluated for its diagnostic utility for rapid detection of anaerobes.

Follow up of tuberculous cases Pus specimens with acid-fast bacilli on ZN stain were inoculated on Löwenstein-Jensen medium and incubated at $37{ }^{\circ} \mathrm{C}$ for $8-12$ weeks. Colonies obtained were confirmed to be acid-fast by $\mathrm{ZN}$, and then were identified by conventional methods, such as rate of growth, pigment production, niacin accumulation and nitrate reduction test (Baron et al., 1994).

Follow up of fungal cases In the pus specimen that showed the presence of fungal filaments on Gram stain, $\mathrm{KOH}(10 \%)$ mount was prepared, and observed under low and high power. The pus specimen was further inoculated on Sabouraud dextrose agar with and without antibiotic, at room temperature and at $37^{\circ} \mathrm{C}$. Colonies obtained were subjected to slide cultures and morphology was studied using lactophenol cotton blue stain. Identification of fungus was made on the basis of gelatin liquefaction and growth at $42{ }^{\circ} \mathrm{C}$ (Larone, 1979; Sutton et al., 1998).

Statistical analysis The data collected were analysed for significance with Fisher's exact test and Pearson's chi-square test using appropriate statistical software (SPSS v 13.5; SPSS) (GraphPad Instat; GraphPad Software).

\section{RESULTS}

This study included 75 patients with brain abscess operated in our hospital from January 2001 to June 2005. Patients had a wide age range, from 6 weeks to 65 years. The majority $(33.3 \%)$ of the patients belonged to the age group 11-20 years. Brain abscess is an uncommon but serious life-threatening infection in children less than 2 years. We encountered four such cases. A preponderance of males over females (55:20) was found amongst the patients (Fig. 1).

Of the 75 patients in this study, a solitary abscess was seen in 66 patients and multiple abscesses were seen in 7 (9.3\%) patients. Two patients presented with a subdural empyema. In the multiple abscess group, five were children and two were adults. Out of these five paediatric cases, three patients were below 2 years of age. The youngest of this group was a 6-weeks-old infant who presented with multiple brain abscesses.

The patients had symptoms suggestive of raised intracranial pressure, i.e. headache and vomiting. Fifty-nine $(78.67 \%)$ of the patients presented with headache and fifty-three $(70.70 \%)$ had vomiting. Fever was present in $65(86.67 \%)$ patients. Headache, fever and vomiting made an important triad. This triad was present in $50.7 \%$ patients. Other symptoms included convulsions, hydrocephalus and epilepsy (Table 1). The period between the onset of symptoms and admission in this study was as follows: 0-7 days $(n=12), 8-15$ days $(n=39), 16-30$ days $(n=23)$ and more than 30 days $(n=1)$. The majority $(70.70 \%)$ of the patients were at consciousness level 1 at the time of admission.

The presence of a predisposing factor precipitating a brain abscess was found in $70.67 \%$ of the patients in the present study. Chronic suppurative otitis media (CSOM) $(49.33 \%)$ was found to be the most important source of intracranial suppuration. The duration of ear discharge was from 6 months to many years. Otogenic brain abscesses were solitary and located mainly in the temporal lobe or the cerebellum. Analysis showed significant association between the affected lobe and predisposing factors. In the



Fig. 1. Age and gender distribution of brain abscess patients. White bars, female patients; grey bars, male patients. 
Table 1. Signs and symptoms of brain abscess patients

\begin{tabular}{|lcc|}
\hline Sign/symptom & No. & Percentage \\
\hline Fever & 65 & 86.67 \\
Headache & 59 & 78.67 \\
Vomiting & 53 & 70.67 \\
Convulsions & 13 & 17.33 \\
Hydrocephalus & 5 & 6.67 \\
Epilepsy & 5 & 6.67 \\
Neck stiffness & 4 & 5.33 \\
Visual complaints & 4 & 5.33 \\
Meningitis & 2 & 2.67 \\
Papilloedema & 1 & 1.33 \\
Hemiparesis & 1 & 1.33 \\
Cyanosis & 1 & 1.33 \\
Photophobia & 1 & 1.33 \\
Speech affected, facial palsy & 1 & 1.33 \\
Consciousness at admission & & \\
Level 1 & 53 & 70.7 \\
Level 4 & 17 & 22.7 \\
Level 2 & 4 & 5.3 \\
Level 3 & 1 & 1.3 \\
\hline
\end{tabular}

present study, six ( $8 \%$ ) of the patients who had congenital heart defect (CHD) developed brain abscess. All these patients had tetralogy of Fallot. In $22(29.33 \%)$ patients, no obvious cause was found, hence the abscesses were described as 'cryptogenic'. Other predisposing factors along with the lobe affected are listed in Table 2.

Gram and ZN stains were performed on all specimens. A combination of these staining techniques gave a clue to the identity of the aetiological agent of the brain abscess in 51 $(67.3 \%)$ cases. Gram staining was positive in $47(62 \%)$ of cases and $\mathrm{ZN}$ staining was positive in 4 patients.

Out of 75 pus specimens, $45(60 \%)$ yielded growth of micro-organisms upon culture. Monomicrobial aetiology was seen in 40 cases. Forty-one (54.7\%) abscesses were found to be pyogenic brain abscesses, three $(4.0 \%)$ grew mycobacteria, and from one $(1.3 \%)$ a fungus was isolated. Pyogenic brain abscesses comprised brain abscesses due to aerobes $(33.33 \%)$, anaerobes $(17.33 \%)$, and a mixture of aerobes and anaerobes $(4.0 \%)$. The most common isolate was Streptococcus $(n=15)$, and in 11 cases this organism was found as the sole isolate. In four cases, Streptococcus was isolated along with other organisms. Streptococcus comprised $\alpha$-haemolytic Streptococcus, $\beta$-haemolytic Streptococcus, Enterococcus avium and other non-haemolytic species of Streptococcus (Table 3).

Amongst anaerobes, Bacteroides fragilis predominated, followed by Prevotella melaninogenica (Table 3). Direct GLC analysis of pus specimens from the patients revealed a good correlation of multiple volatile fatty acids with isolation of anaerobic bacteria, as compared to specimens without anaerobes in culture. Multiple peaks were observed in 10 $(83.33 \%)$ pus specimens, which revealed the presence of anaerobes upon culture. A single peak was present in 14 $(56 \%)$ pus specimens that revealed the presence of aerobes upon culture, while the specimens where no organisms were isolated upon culture showed an absence of peaks (74.07\%).

An attempt was made to study the association between the predisposing factors and organisms isolated. Table 4 shows that 12 out of 13 anaerobes were isolated from the otogenic brain abscesses. However, the statistical analysis revealed the association to be insignificant.

Antibiotic sensitivity results showed that Gram-positive aerobes were sensitive to cefotaxime $(83 \%)$, gentamicin $(81 \%)$ and chloramphenicol $(80 \%)$. The majority of Gram-negative aerobic isolates were found to be sensitive to chloramphenicol $(88 \%)$, gentamicin $(56 \%)$ and cefotaxime $(58 \%)$. Gram-negative anaerobes were found to be sensitive to metronidazole $(100 \%)$, chloramphenicol $(85 \%)$ and cefotaxime $(78 \%)$. Gram-positive anaerobic

Table 2. Association between lobe affected and predisposing factors

For Fisher's exact test (exact $P$ value) $<0.0001$ was considered significant and for Pearson chi-square test $<0.0001$ was considered significant.

\begin{tabular}{|c|c|c|c|c|c|c|c|c|}
\hline Predisposing factor & No. & Temporal & Cerebellar & Frontal & Parietal & Thalamic & Multiple & $\begin{array}{l}\text { Subdural } \\
\text { empyema }\end{array}$ \\
\hline CSOM & 37 & 25 & 10 & 1 & 0 & 0 & 0 & 1 \\
\hline Cryptogenic & 22 & 4 & 3 & 7 & 5 & 0 & 2 & 1 \\
\hline Trauma & 6 & 1 & 0 & 3 & 1 & 1 & 0 & 0 \\
\hline Dental & 1 & 0 & 0 & 1 & 0 & 0 & 0 & 0 \\
\hline Postcraniotomy & 1 & 0 & 0 & 1 & 0 & 0 & 0 & 0 \\
\hline CSOM-CHD & 1 & 0 & 1 & 0 & 0 & 0 & 0 & 0 \\
\hline Sinusitis & 1 & 0 & 0 & 0 & 0 & 0 & 1 & 0 \\
\hline Total & 75 & 30 & 14 & 15 & 8 & 1 & 5 & 2 \\
\hline
\end{tabular}


Table 3. Culture results

\begin{tabular}{|c|c|c|c|}
\hline Nature of isolate & No. of cases & Organism isolated & No. of isolates \\
\hline \multicolumn{4}{|l|}{ Aerobes } \\
\hline \multirow[t]{10}{*}{ Single species } & \multirow[t]{10}{*}{$24(32 \%)$} & Streptococcus spp. (non-haemolytic) & $5(6.67 \%)$ \\
\hline & & $\beta$-Haemolytic streptococci & $3(4 \%)$ \\
\hline & & Enterococcus avium & $2(2.67 \%)$ \\
\hline & & Viridans streptococci & $1(1.33 \%)$ \\
\hline & & Staphylococcus aureus & $6(8 \%)$ \\
\hline & & Pseudomonas spp. & $2(2.67 \%)$ \\
\hline & & Proteus mirabilis & $2(2.67 \%)$ \\
\hline & & Enterobacter aerogenes & $1(1.33 \%)$ \\
\hline & & Escherichia coli & $1(1.33 \%)$ \\
\hline & & Morganella morganii & $1(1.33 \%)$ \\
\hline Mixed species & $1(1.33 \%)$ & Proteus vulgaris + Enterococcus avium & $1(1.33 \%)$ \\
\hline \multicolumn{4}{|l|}{ Anaerobes } \\
\hline \multirow[t]{6}{*}{ Single species } & \multirow{6}{*}{$12(16 \%)$} & Bacteroides fragilis & $6(8 \%)$ \\
\hline & & Prevotella melaninogenica & $1(1.33 \%)$ \\
\hline & & Prevotella denticola & $2(2.67 \%)$ \\
\hline & & Peptococcus niger & $1(1.33 \%)$ \\
\hline & & Peptostreptococcus spp. & $1(1.33 \%)$ \\
\hline & & Fusobacterium necrophorum & $1(1.33 \%)$ \\
\hline Mixed species & $1(1.33 \%)$ & Bacteroides fragilis + Prevotella melaninogenica + Bacteroides capillosus & $1(1.33 \%)$ \\
\hline \multirow[t]{3}{*}{ Aerobes and anaerobes } & \multirow[t]{3}{*}{$3(4 \%)$} & $\beta$-Haemolytic streptococci + Actinomyces odontolyticus & $1(1.33 \%)$ \\
\hline & & Viridans streptococci + Prevotella melaninogenica & $1(1.33 \%)$ \\
\hline & & Streptococcus spp. (non-haemolytic) + Bacteroides fragilis & $1(1.33 \%)$ \\
\hline Mycobacteria & $3(4 \%)$ & Mycobacterium tuberculosis & $3(4 \%)$ \\
\hline Fungi & $1(1.33 \%)$ & Cladophialophora bantiana & $1(1.33 \%)$ \\
\hline No organisms isolated & $30(40 \%)$ & & \\
\hline Total & 75 & & $45(60 \%)$ \\
\hline
\end{tabular}

cocci were found to be sensitive to penicillin (100\%), chloramphenicol $(100 \%)$, tetracycline $(100 \%)$ and cephotaxime $(100 \%)$.

The mortality amongst the patients was $9.5 \%$. Statistical analysis revealed a significant association between age and level of consciousness, and with mortality (Tables 5 and 6). However, there was no significant association observed between culture results, number of abscesses and the mortality. Out of seven patients who died in this study, four belonged to the paediatric age group. All the seven patients had an altered sensorium at the time of admission (Table 7 ). In the present study $5.4 \%$ death was seen with otogenic brain abscesses, $13 \%$ with cryptogenic brain abscesses and $16.6 \%$ with brain abscesses associated with congenital heart disease.

Table 4. Association between predisposing factors and organisms isolated

For Pearson chi-square test $>0.0001$ was considered not significant.

\begin{tabular}{|c|c|c|c|c|c|c|c|}
\hline Predisposing factor & Total & Anaerobe & Aerobe & $\begin{array}{c}\text { Mycobacterium } \\
\text { tuberculosis }\end{array}$ & Fungus & $\begin{array}{c}\text { Mixture of aerobes } \\
\text { and anaerobes }\end{array}$ & $\begin{array}{c}\text { No organisms } \\
\text { isolated }\end{array}$ \\
\hline CSOM & 37 & 11 & 8 & 0 & 0 & 1 & 17 \\
\hline Cryptogenic & 22 & 0 & 11 & 3 & 1 & 1 & 6 \\
\hline Trauma & 6 & 1 & 1 & 0 & 0 & 0 & 4 \\
\hline $\mathrm{CHD}$ & 6 & 0 & 4 & 0 & 0 & 1 & 1 \\
\hline Dental & 1 & 0 & 1 & 0 & 0 & 0 & 0 \\
\hline Postcraniotomy & 1 & 0 & 0 & 0 & 0 & 0 & 1 \\
\hline CSOM-CHD & 1 & 1 & 0 & 0 & 0 & 0 & 0 \\
\hline Sinusitis & 1 & 0 & 0 & 0 & 0 & 0 & 1 \\
\hline Total & 75 & 13 & 25 & 3 & 1 & 3 & 30 \\
\hline
\end{tabular}


Table 5. Age versus outcome in the patients

For Fisher's exact test (exact $P$ value) $<0.0001$ was considered significant and for Pearson chi-square test $<0.0001$ was considered significant.

\begin{tabular}{|lclr|}
\hline \multirow{3}{*}{ Age (years) } & \multicolumn{3}{c|}{ Outcome } \\
\cline { 2 - 4 } & Recovered & \multicolumn{1}{c|}{ Died } & \multicolumn{1}{c|}{ Total } \\
\hline$\leqslant 2$ & $2(50 \%)$ & $2(50 \%)$ & $4(100 \%)$ \\
$3-10$ & $2(66.7 \%)$ & $1(33.3 \%)$ & $3(100 \%)$ \\
$11-20$ & $22(95.7 \%)$ & $1(4.3 \%)$ & $23(100 \%)$ \\
$21-30$ & $18(100 \%)$ & $0(0 \%)$ & $18(100 \%)$ \\
$31-40$ & $16(94.11 \%)$ & $1(5.89 \%)$ & $17(100 \%)$ \\
$41-50$ & $4(66.7 \%)$ & $2(33.3 \%)$ & $6(100 \%)$ \\
$51-60$ & $1(100 \%)$ & $0(0 \%)$ & $1(100 \%)$ \\
$61-70$ & $1(100 \%)$ & $0(0 \%)$ & $1(100 \%)$ \\
Total & $66(90.41 \%)$ & $7(9.59 \%)$ & $73^{*}(100 \%)$ \\
\hline
\end{tabular}

${ }^{*}$ Two patients went against medical advice.

\section{DISCUSSION}

The current study highlights that brain abscess continues to pose a significant problem as we dealt with 75 cases in the 5 year study period, giving a mean of 15 cases per year. From this study we noticed that brain abscess could occur at any age. The most affected age group was 11-20 years. However, the majority $(80 \%)$ of cases occurred between the second and fourth decades of life. McClelland et al. (1978) found that this disease occurs most often in the middle decades of life. Sinha et al. (2003) reported $74.89 \%$ of their patients were below 20 years of age. A brain abscess in neonates and infants is a rare condition, but there are occasional reports of brain abscess in infants documented

Table 6. Consciousness at the time of admission and outcome

For Fisher's exact test (exact $P$ value) $<0.0001$ was considered significant and for Pearson chi-square test $<0.0001$ was considered significant.

\begin{tabular}{|lccr|}
\hline $\begin{array}{l}\text { Level of } \\
\text { consciousness } \\
\text { at time of } \\
\text { admission }\end{array}$ & \multicolumn{3}{c|}{ Outcome } \\
\cline { 2 - 4 } & Recovered & Died & Total \\
\hline Level 1 & $51(100 \%)$ & $0(0 \%)$ & $51(100 \%)$ \\
Level 2 & $4(100 \%)$ & $0(0 \%)$ & $4(100 \%)$ \\
Level 3 & $1(100 \%)$ & $0(0 \%)$ & $1(100 \%)$ \\
Level 4 & $10(58.9 \%)$ & $7(41.1 \%)$ & $17(100 \%)$ \\
Total & $66(90.41 \%)$ & $7(9.59 \%)$ & $73^{\star}(100 \%)$ \\
\hline
\end{tabular}

${ }^{\star}$ Two patients went against medical advice. in the literature (Erdogan et al., 2002; Han et al., 2002). Males were found to be more affected than females in the present study, irrespective of the age group. Similar observations have been reported from different parts of world (Beller et al., 1973; McClelland et al., 1978; Sinha et al., 2003; Bhand, 2004). It is clear from all these studies that males are more vulnerable to brain abscess irrespective of the geographical region. The reasons for such a distribution are not very clear (Fig. 1).

Brain abscesses are usually solitary, although multiple abscesses occurring simultaneously in the brain have been reported. Multiple brain abscesses are usually very rare below 2 years of age (Mathisen \& Johnson, 1997); although we encountered two such cases. One was a 6-week-old infant and the other was an 18-month-old baby. Multiple brain abscesses is one of the major features of metastatic abscesses, which occur through haematogenous dissemination from a remote site of infection. In the present study, the 18-monthold baby had cyanotic congenital heart disease associated with bacterial endocarditis. However, in the 6-week-old infant the source of infection remained obscure.

Headache, fever, and vomiting made an important triad of symptoms in the present study, which were present in $50.7 \%$ of patients. Fever has been reported as the important presenting symptom in brain abscess patients by many workers; however, the absence of fever does not exclude the diagnosis. Vomiting is another common symptom suggestive of raised intracranial pressure. In the present study, only $17.33 \%$ presented with the classic triad of headache, fever and neurological deficit, hence this triad cannot be used as a sensitive marker for the diagnosis of brain abscess. A similar finding has been reported by $\mathrm{Ni}$ et al. (2004). An alteration in the level of consciousness is usually present in up to two-thirds of the patients (Morgan et al., 1973; Mampalam \& Rosenblum, 1988). In the present study $22.7 \%$ of the patients were brought to the hospital in unconscious state (Table 1). The state of consciousness of the patient at the time of admission is usually taken as a reliable prognostic marker.

Out of the 75 patients, $53(70.67 \%)$ had a demonstrable infectious source leading to the intracranial suppuration. CSOM was found to be the major source of infection (Table 2). In most large series of brain abscesses from developing countries, middle ear infection has been reported to be the commonest source of intracranial suppuration. This has been reflected in various studies from India (Bharadwaj \& Joshi, 1988; Lakshmi et al., 1993; Sinha et al., 2003). This clearly indicates that an ear infection is often neglected and not treated aggressively in developing countries, while in developed countries the incidence of complication of CSOM has come down to $0.04 \%$ of all cases of suppurative ear disease (Osma et al., 2000). Our study we also noticed that otogenic abscesses are usually solitary and located in either the temporal or the cerebellar lobe. Similar reports have appeared in the literature (Carey et al., 1972; Samson \& Clark, 1973). 
Table 7. Features of fatal intracranial infection

\begin{tabular}{|c|c|c|c|c|c|c|}
\hline Age & Gender & No. of abscesses & Location of abscesses & Clinical presentation & Aetiology & $\begin{array}{l}\text { Level of consciousness at time of } \\
\text { admission/treatment }\end{array}$ \\
\hline 6 weeks & Male & Multiple & Temporal, parietal & $\begin{array}{l}\text { Irritable, sunset eyes, bulging } \\
\text { fontanelles, hydrocephalus }\end{array}$ & Enterobacter aerogenes & $\begin{array}{l}\text { Level } 4 \text { / cefotaxime, gentamicin, } \\
\text { metronidazole }\end{array}$ \\
\hline 18 months & Female & Multiple & $\begin{array}{l}\text { Frontal, parietal, } \\
\text { thalamic, pontiac }\end{array}$ & $\begin{array}{l}\text { CHD, tetralogy of Fallot, } \\
\text { hydrocephalus, cyanosis of sole } \\
\text { and palms since birth, fever, } \\
\text { repeated lower respiratory tract } \\
\text { infection, child unable to move }\end{array}$ & $\beta$-Haemolytic streptococci & $\begin{array}{l}\text { Level } 4 / \text { magnamycin, amikacin, } \\
\text { metronidazole }\end{array}$ \\
\hline $3-10$ years & Female & Single & Temporal & CSOM, headache, vomiting, fever & $\begin{array}{l}\text { Bacteroides fragilis, Prevotella } \\
\text { melaninogenica, Bacteroides } \\
\text { capillosus }\end{array}$ & $\begin{array}{l}\text { Level } 4 / \text { cefotaxime, amikacin, } \\
\text { cefepime, metronidazole }\end{array}$ \\
\hline $11-20$ years & Female & Subdural empyema & $\begin{array}{l}\text { Temporal abscess with } \\
\text { subdural collection }\end{array}$ & $\begin{array}{l}\text { CSOM, fever, convulsions, } \\
\text { hydrocephalus, operated for } \\
\text { tuberculoma in 1997, shunt } \\
\text { infection in } 1998\end{array}$ & Proteus mirabilis & $\begin{array}{l}\text { Level } 4 \text { / antituberculous treatment } \\
\text { taken for } 2 \text { years; magnamycin, } \\
\text { cefotaxime, amikacin, gentami- } \\
\text { cin, metronidazole }\end{array}$ \\
\hline $31-40$ years & Male & Single & Frontal & $\begin{array}{l}\text { History of trauma, vomiting, } \\
\text { generalized tonic-clonic } \\
\text { convulsions, fever }\end{array}$ & Fusobacterium necrophorum & $\begin{array}{l}\text { Level 4/ magnamycin, amikacin, } \\
\text { metronidazole }\end{array}$ \\
\hline $41-50$ years & Male & Single & Frontal & $\begin{array}{l}\text { Fever, breathlessness, left } \\
\text { hemiparesis, history of a fall, } \\
\text { giddiness, seizures }\end{array}$ & Mycobacterium tuberculosis & $\begin{array}{l}\text { Level } 4 \text { / magnamycin, amikacin, } \\
\text { metronidazole, cefpirome, iso- } \\
\text { niazide, rifampicin, ethambutol, } \\
\text { pyrizinamide }\end{array}$ \\
\hline $41-50$ years & Male & Single & Frontal & $\begin{array}{l}\text { Fever, vomiting, diabetic } \\
\text { ketoacidosis, haematuria }\end{array}$ & $\beta$-Haemolytic streptococci & $\begin{array}{l}\text { Level } 4 / \text { cefotaxime, amikacin, } \\
\text { metronidazole }\end{array}$ \\
\hline
\end{tabular}


Intracranial lesions frequently occur in association with congenital malformation of the heart. Intracranial abscess and cerebral thrombosis are the two most serious complications of the brain due to congenital heart disease (Kagawa et al., 1983). When such a CHD remains uncorrected, it becomes a nidus for bacteria to settle and become a source of bacteraemia. Tetralogy of Fallot and transposition of the great vessels are the most commonly cited predisposing factors (Fischer et al., 1981). The peak incidence is between 4 and 7 years of age, although cases of brain abscess may occur in adults with CHD (Kagawa et al., 1983). We encountered six ( $8 \%)$ brain abscess cases with associated congenital heart disease. All of them had tetralogy of Fallot.

With the increasing incidence of road accidents, head trauma has become an important predisposing factor of brain abscess (Lakshmi et al., 1993). In the present study $8 \%$ of the brain abscesses we encountered were such cases. Twenty-two (29.3\%) abscesses remained cryptogenic. Transient bacteraemia of dental or abdominal origin possibly could account for the origin of some of these cryptogenic abscesses. Although larger series would be required to assess the validity of such a hypothesis.

The brain lobe affected usually depends on the predisposing factor that led to the development of the brain abscess. In our studies, the most common lobe involved was the temporal lobe because CSOM was found to be the major predisposing factor (Table 2). We found that $67.6 \%$ of the otogenic abscesses were in the temporal lobe. Similar observations have been reported by others (Bharadwaj \& Joshi, 1988; Sinha et al., 2003; Bhand, 2004).

The identification of the causative organisms is important for appropriate management. Microscopy results clearly indicated that if the neurosurgeon uses the expertise of microbiologists, simple techniques like Gram stain and ZN stain would help in the selection of proper therapy. This is true especially for tuberculous and fungal brain abscesses, which are difficult to distinguish clinically and radiologically from pyogenic ones.

Cultures were positive in $45(60 \%)$ cases and 40 pus specimens yielded a single isolate. A culture positivity for brain abscess pus specimens of $44-100 \%$ has been reported in the literature (De Louvois et al., 1977; Chandramuki et al., 1980; Sinha et al., 2003). Monomicrobial aetiology was also found to be a feature of brain abscesses (Chandramuki et al., 1980; Lakshmi et al.,1993; De et al., 2000). Aerobes dominated over anaerobes in the present study (Table 3). Similar findings have been reported in the literature, but there are also reports of anaerobes outnumbering aerobes (Chandramuki et al., 1980; Bharadwaj \& Joshi, 1988).

In the present study, streptococci were isolated from 15 patients. In 11 of the cases, streptococci were isolated as a single isolate, and in the remaining 4 cases streptococci were isolated with either aerobes or anaerobes. Among the
15 patients, 13 had a single abscess and 2 had multiple abscesses. Common predisposing factors found in these patients were CSOM in five cases, CHD in four cases and in six cases the cause was unknown. All the five cases where the predisposing factor was CSOM showed involvement of the temporal lobe. Out of four patients with CHD, two of them showed the involvement of parietal lobe, while the remaining two had multiple brain abscesses (frontal, parietal, pontine and parietal, frontal, and occipital). Out of these six cryptogenic cases, three patients had frontal lobe abscess, while two showed parietal lobe involvement and one had a cerebellar abscess. In the present study, streptococci affected almost all parts of the brain. De Louvois et al. (1977) also reported isolation of streptococci from abscesses of all types, and all sites.

As shown in Table 3, 13 (17.33\%) pus specimens yielded a pure growth of anaerobes, while 3 specimens $(4 \%)$ showed a mixed growth of aerobes and anaerobes. Anaerobic brain abscesses are often associated with CSOM. In the present study, 12 out of 13 specimens containing anaerobes were associated with CSOM. Otogenic infection was found to be the most common source of infection for anaerobic brain abscesses reported in the various studies. Anaerobic Gramnegative bacilli belonging to the family Bacteroidaceae were the predominant isolate reported from brain abscesses. The most common anaerobe isolated in this study was $B$. fragilis. All the $B$. fragilis isolated in the present study were from post-CSOM brain abscesses.

For $30(40 \%)$ specimens in this study no organisms were isolated upon culture. The high incidence of such cultures may be because the samples were collected from a tertiary care centre and patients had undergone a treatment of long duration with broad spectrum of antibiotics before they reported to the hospital. It has been reported that for 9$63 \%$ of primary pus specimens from abscesses of the central nervous system no organisms were isolated upon culture (Gregory et al., 1967). These cases also may have had a non-bacterial aetiology, which was not specifically looked for in the present study.

The empirical antimicrobial regimens commonly recommended for therapy of brain abscess vary from unit to unit. The basis for selecting the antibiotics is usually the site of the lesion and the suspected causative organism had been presumed based on previous scientific data. In vitro antibiotic sensitivity results also showed that a cefotaxime and metronidazole regime, which is usually used in most of the neurosurgery units, is a satisfactory presumptive choice of therapy. Chloramphenicol was found to be a potentially useful alternative.

Mortality ranging from 8 to $53 \%$ has been reported in other studies. Various factors contribute to mortality, the important factors being the age of the patient, the level of consciousness at the time of admission, multiplicity of abscesses and the nature of the infection. In the present study $9.5 \%$ mortality was observed, and a statistically significant association was shown between the age of the 
Table 8. Reports of some studies on brain abscesses internationally

\begin{tabular}{|c|c|c|c|c|c|c|c|c|}
\hline Date of publication & $\begin{array}{l}\text { Location } \\
\text { (country) }\end{array}$ & Duration & $\begin{array}{l}\text { No. of } \\
\text { cases }\end{array}$ & $\begin{array}{l}\text { Cases per } \\
\text { year }\end{array}$ & $\begin{array}{c}\text { Predominant } \\
\text { predisposing cause }\end{array}$ & $\begin{array}{l}\text { Predominant } \\
\text { organism }\end{array}$ & Mortality (\%) & Factor governing mortality \\
\hline Beller et al. (1973) & Israel & $\begin{array}{r}1941-1971 \\
(30 \text { years })\end{array}$ & 89 & 3 & $\begin{array}{l}\text { Abscesses of ear, } \\
\text { nose }\end{array}$ & $\begin{array}{l}\text { Staphylococcus } \\
\text { aureus }\end{array}$ & 40 & $\begin{array}{l}\text { Staphylococci caused the largest } \\
\text { number of deaths }\end{array}$ \\
\hline Carey et al. (1972) & Minnesota & $\begin{array}{r}1946-1965 \\
(20 \text { years })\end{array}$ & 86 & 4 & $\begin{array}{l}\text { Haematogenous or } \\
\text { metastatic abscess }\end{array}$ & & 53 & $\begin{array}{l}\text { Multiple and brain stem abscesses, } \\
\text { delayed and missed diagnosis, pre- } \\
\text { operative neurological status }\end{array}$ \\
\hline Morgan et al. (1973) & Tennessee & $\begin{array}{r}1946-1971 \\
(26 \text { years })\end{array}$ & 88 & 3 & Otogenic abscess & $\begin{array}{l}\text { Streptococci and } \\
\text { staphylococci }\end{array}$ & 29.1 & Pre-operative level of consciousness \\
\hline McClelland et al. (1978) & Northern Ireland & $\begin{array}{r}1947-1976 \\
(30 \text { years })\end{array}$ & 172 & 6 & CSOM & Staphylococcus & 53 & $\begin{array}{l}\text { Gram-positive coccal infections had } \\
\text { an overall mortality of } 40 \% \text {, } \\
\text { Gram-negative bacilli infections } \\
\text { had a mortality of } 50 \% \text {, with } \\
\text { Proteus the mortality rose to } 80 \%\end{array}$ \\
\hline $\begin{array}{l}\text { Samson \& Clark } \\
\text { (1973) }\end{array}$ & Dallas, TX, USA & $\begin{array}{r}1961-1971 \\
(11 \text { years })\end{array}$ & 42 & 4 & $\begin{array}{l}\text { Otitic and sinus } \\
\text { infection }\end{array}$ & Staphylococcus aureus & 42.8 & $\begin{array}{l}\text { Mortality of brain abscess related to } \\
\text { the space it occupies }\end{array}$ \\
\hline $\begin{array}{l}\text { Karandanis \& } \\
\text { Shulman (1975) }\end{array}$ & Atlanta, GA, USA & $\begin{array}{r}1963-1973 \\
(11 \text { years })\end{array}$ & 25 & 2 & $\begin{array}{l}\text { Sinus, mastoid, } \\
\text { dental infections }\end{array}$ & & 64 & $\begin{array}{l}\text { Coma on admission, multiple deep- } \\
\text { seated or ruptured abscesses, } \\
\text { inaccurate diagnosis }\end{array}$ \\
\hline De Louvois et al. (1977) & London & 40 months & 46 & 14 & Otitic & Streptococcus & 24 & \\
\hline Fischer et al. (1981) & Boston, MA, USA & $\begin{array}{r}1945-1980 \\
(36 \text { years })\end{array}$ & 94 & 3 & CHD, otitis, sinus & Streptococcus & $\begin{array}{l}1945-197036 \%, \\
1971-198014 \%\end{array}$ & $\begin{array}{l}\text { Presence of coma at the time of } \\
\text { treatment }\end{array}$ \\
\hline $\begin{array}{l}\text { Chandramuki et al. } \\
\text { (1980) }\end{array}$ & Bangalore, India & $\begin{array}{c}1977-1979 \\
(3 \text { years })\end{array}$ & 50 & 17 & CSOM & $\begin{array}{l}\text { Bacteroides fragilis, } \\
\text { anaerobic strep- } \\
\text { tococci }\end{array}$ & 16 & \\
\hline Bharadwaj \& Joshi (1988) & Pune, India & 2 years & 34 & 17 & CSOM & Bacteroides fragilis & & \\
\hline Ayyagari et al. (1983) & Chandigarh, India & $\begin{array}{l}\text { Apr 1979-Dec } \\
1980 \text { (21 months) }\end{array}$ & 45 & 26 & CSOM & Staphylococcus aureus & 13.3 & Poor general condition of patients \\
\hline Yang \& Zhao (1993) & China & $\begin{array}{r}1980-1991 \\
(12 \text { years })\end{array}$ & 140 & 12 & $\begin{array}{l}\text { 1980-1985 Contiguous } \\
\text { infection (CSOM) } \\
\text { 1986-1991 Cryptogenic } \\
\text { abscess }\end{array}$ & $\begin{array}{l}\text { Staphylococcus aureus, } \\
\text { Proteus vulgaris }\end{array}$ & 7.9 & Condition of patients on admission \\
\hline Lakshmi et al. (1993) & Hyderabad, India & $\begin{array}{l}\text { Jan 1987-July } 1991 \\
\text { (55 months) }\end{array}$ & 50 & 11 & CSOM & Staphylococcus aureus & & \\
\hline De et al. (2000) & $\begin{array}{l}\text { Sion Hospital, } \\
\text { Mumbai, India }\end{array}$ & $\begin{array}{c}1998-1999 \\
(2 \text { years })\end{array}$ & 38 & 19 & Sinusitis & Staphylococcus aureus & 7.9 & \\
\hline Sinha et al. (2003) & Delhi, India & $\begin{array}{r}1984-2003 \\
(20 \text { years })\end{array}$ & 268 & 13 & CSOM & Streptococcus & 11 & $\begin{array}{l}\text { Patients with CHD and those hav- } \\
\text { ing multiple abscesses, patients } \\
\text { with low Glasgow coma scale }\end{array}$ \\
\hline Bhand (2004) & Larkhana & $\begin{array}{l}\text { July } 1998-\text { June } \\
2003 \text { (5 years) }\end{array}$ & 82 & 16 & Otogenic abscess & $\begin{array}{l}\text { Bacteroides } \\
\text { Streptococcus }\end{array}$ & 22 & \\
\hline Present study & $\begin{array}{l}\text { Sir J. J. Hospital, } \\
\text { Mumbai, India }\end{array}$ & $\begin{array}{l}\text { Jan } 2001-\text { June } \\
2005 \text { (5 years })\end{array}$ & 75 & 15 & CSOM & $\begin{array}{l}\text { Streptococcus spp., } \\
\text { Bacteroides fragilis }\end{array}$ & 9.5 & $\begin{array}{l}\text { Age and consciousness at the time } \\
\text { of admission }\end{array}$ \\
\hline
\end{tabular}


patient and mortality (Table 5). Beller et al. (1973) could not find a significant correlation between the age of the patient and mortality in their study.

The most successful predictor of clinical outcome for patients with brain abscess was the extent of neurological compromise at the time of presentation and diagnosis (Table 6). All the patients that died in this study had an altered sensorium at the time of admission. The level of consciousness at presentation has been shown by other authors to be of great prognostic value (Karandanis \& Shulman, 1975; McClelland et al., 1978). We could not find any significant association between the identity of the causal organism and mortality. Out of the seven patients who died, four brain abscesses were due to aerobes, two were due to anaerobes and one was due to Mycobacterium tuberculosis (Table 7). According to Beller et al. (1973), staphylococci cause the largest number of deaths, whilst there seemed to be a low death rate for patients with abscesses produced by streptococci in monobacterial growth. In our study, there was no death in patients who developed brain abscess due to staphylococci, while there were two deaths due to $\beta$ haemolytic streptococci. In the present study, patients with Gram-positive cocci had an overall mortality of $8 \%$, those with Gram-negative bacilli had a mortality of $30.7 \%$. McClelland et al. (1978) reported $40 \%$ mortality with Gram-positive cocci and $50 \%$ mortality with Gram-negative bacilli. They also noted that Proteus infections were associated with a high mortality. This may have been due, in some part, to the pathogenicity of the organism. Out of three cases that were due to Proteus spp., we encountered death in one patient. The virulence of these organisms is difficult to assess due to the small number of such cases. The question as to whether polybacterial growth carries a higher mortality is difficult to answer. It seems that the prognosis in such abscesses depends on the most virulent of the various organisms. In the present study out of seven deaths, six were due to monomicrobial aetiology. In one case, there were three anaerobes; this was a purely anaerobic abscess associated with meningitis due to B. fragilis, Bacteroides capillosus and Prevotella melaninogenica. However, there were no deaths in the group where no organisms were isolated upon culture.

In the present study, two (28.5\%) patients who died had multiple brain abscesses. Beller et al. (1973) reported $63 \%$ mortality amongst patients having multiple brain abscesses. Carey et al. (1972) reported $100 \%$ mortality in patients with multiple brain abscesses. Our results also showed that otogenic brain abscesses have a better prognosis than haematogenous abscesses. Sinha et al. (2003) reported a similar finding.

On reviewing the available published literature it can be concluded that there has been a decrease in mortality due to brain abscesses since 1975 , as seen in different studies (Table 8). This may be due to advances in diagnostic modalities, antibiotic regimens and surgical techniques. Most of the studies have also shown that the level of consciousness of these patients at the time of admission predicted the outcome. Table 8 shows that brain abscesses still remain a major problem in India. Although there is no documented evidence on the incidence of brain abscesses from India, reports have appeared in the literature from various centres. These studies are from the later half of the 20th century, which reports on average 17 cases per year. However, in the USA, brain abscess was common in the first half of the 20th century, but then with the introduction of effective antimicrobial therapy for purulent infections of the mastoid process and paranasal sinuses, there has been a significant reduction in the incidence of all intracranial complications, including brain abscess and subdural empyema (Nathoo et al., 1999). Paracranial suppuration is still the most common source of intracranial abscesses in India, with no major change in bacteriology. Earlier diagnosis and aggressive treatment of these conditions will certainly reduce the incidence of such brain abscesses. The multidisciplinary approach, involving a neurosurgeon, neuroradiologist, otolaryngologist, paediatrician and an infectious-disease specialist, will help in the early identification and targeted treatment of this clinical condition.

\section{ACKNOWLEDGEMENTS}

The authors would like to acknowledge Dr Abhiram Kasbe, Associate Professor, Department of Preventative and Social Medicine, Nair Hospital, Mumbai, India, for the statistical analysis. We would also like to thank the editorial team of JMM for their assistance with the manuscript.

\section{REFERENCES}

Ayyagari, A., Pancholi, V. K., Kak, V. K., Kumar, N., Khosla, V. K., Agarwal, K. C. \& Gulati, D. R. (1983). Bacteriological spectrum of brain abscess with special reference to anaerobic bacteria. Indian $J$ Med Res 77, 182-186.

Baron, E. J., Peterson, L. R. \& Finegold, S. M. (1994). Bailey and Scott's Diagnostic Microbiology, 9th edn. St Louis, MO; CV Mosby Company.

Bauer, A. W., Kirby, W. M. M., Herris, J. C. \& Jurek, M. (1966). Antibiotic susceptibility testing by a standardized single method. Am J Clin Pathol 45, 493-496.

Beller, A. J., Sahar, A. \& Praiss, I. (1973). Brain abscess - review of 89 cases over a period of 30 years. J Neurol Neurosurg Psychiatry 36, 757-768.

Bhand, A. A. (2004). Brain abscess - diagnosis \& management. J Coll Physicians Surg Pak 14, 407-410.

Bharadwaj, R. \& Joshi, B. N. (1988). Brain abscesses - a study of the causative organisms with special reference to anaerobes. Indian $J$ Pathol Microbiol 31, 44-48.

Calfee, D. P. \& Wispelwey, B. (1999). Brain abscess, subdural empyema and intracranial epidural abscess. Curr Infect Dis Rep 1, 166-171.

Carey, M. E., Shelley, N., Chou, S. N. \& French, L. A. (1972). Experience with brain abscesses. J Neurosurg 36, 1-9.

Chandramuki, A., Hegde, A. S. \& Reddy, N. (1980). Anaerobic brain abscess - role of metronidazole in chemotherapy. Neurol India 28, 213-218. 
De, A., Das, P., Sharma, A. \& Mathur, M. (2000). Bacteriology of intracranial abscesses with special reference to anaerobes. Indian $J$ Med Microbiol 18, 184-188.

De Louvois, J., Gortval, P. \& Hurley, R. (1977). Bacteriology of abscesses of the central nervous system: a multicentre prospective study. Br Med J 2, 981-984.

Erdogan, E., Izci, Y., Dizer, U. \& Baysefer, A. (2002). Multiple brain abscesses in a baby: case report and review of the literature. Ann Neurosurg 2, 1-6.

Fischer, E. G., McLennan, J. E. \& Suzuki, Y. (1981). Cerebral abscess in children. Am J Dis Child 135, 746-760.

Gregory, D. H., Messner, R. \& Zinnerman, H. H. (1967). Metastatic brain abscesses. A retrospective appraisal of 29 patients. Arch Intern Med 119, 25-31.

Han, S., Lim, D. J., Chung, Y. G., Cho, T. H., Lim, S. J., Kim, W. J., Park, J. Y. \& Suh, J. K. (2002). The multiple brain abscesses associated with congenital pulmonary arterovenous malformations: a case report. $J$ Korean Med Sci 17, 407-411.

Kagawa, M., Takeshita, M., Yato, S. \& Kitamura, K. (1983). Brain abscess in congenital cyanotic heart disease. J Neurosurg 58, 913-917.

Kao, P.T., Tseng, H.K., Liu, C.P., Su, S. C. \& Lee, C.M. (2003). Brain abscess: clinical analysis of 53 cases. J Microbiol Immunol Infect 36, 129-136.

Karandanis, D. \& Shulman, J. A. (1975). Factors associated with mortality in brain abscess. Arch Intern Med 135, 1145-1150.

Lakshmi, V., Rao, R. R. \& Dinkar, I. (1993). Bacteriology of brain abscess - observation on 50 cases. J Med Microbiol 38, 187-190.

Larone, D. H. (1979). Medically Important Fungi: a Guide to Identification, 2nd edn. New York: Harper and Row.

Mampalam, T. J. \& Rosenblum, M. L. (1988). Trends in the management of bacterial brain abscess: a review of 102 cases over 17 years. Neurosurgery 23, 451-457.
Mathisen, G. E. \& Johnson, J. P. (1997). Brain abscess. Clin Infect Dis 25, 763-781.

McClelland, C. J., Craig, B. F. \& Crockard, H. A. (1978). Brain abscess in Northern Ireland: a 30-year community review. J Neurol Neurosurg Psychiatry 41, 1043-1047.

Morgan, H., Wood, M. \& Murphy, F. (1973). Experience with 88 consecutive cases of brain abscess. J Neurosurg 38, 698-704.

Nathoo, N., Nadvi, S. S., van Dellen, J. R. \& Gouws, E. (1999). Intracranial subdural empyemas in the era of computed tomography: a review of 699 cases. Neurosurgery 44, 529-536.

Ni, Y. H., Yeh, K. M., Peng, M. Y., Chou, Y. Y. \& Chang, F. Y. (2004). Community-acquired brain abscess in Taiwan: etiology and probable source of infection. J Microbiol Immunol Infect 37, 231-235.

Osma, U., Cureoglu, S. \& Hosoglu, S. (2000). The complications of chronic otitis media: report of 93 cases. J Laryngol Otol 114, 97-100.

Samson, D. S. \& Clark, K. (1973). A current review of brain abscess. Am J Med 54, 201-210.

Seneviratne, R. S., Navasivaym, P., Perera, S. \& Wickremasinghe, R. S. (2003). Microbiology of cerebral abscess at the neurosurgical unit of the National Hospital of Sri Lanka. Ceylon Med J 48, 14-15.

Sinha, A. K., Mohanty, S., Sharma, V., Choudhury, A., Huda, M. F., Singh, V. P. \& Tiwari, Y. A. (2003). A study of 268 consecutive cases of intracranial suppuration. Neurosciences Today 7, 161-165.

Sutton, D. A., Fothergill, A. W. \& Michael, G. R. (1998). Guide to Clinically Important Fungi, 1st edn. Baltimore, MD: Williams \& Wilkins.

Willis, A. T. \& Phillips, K. D. (1988). Gas liquid chromatography. In Anaerobic Infections Clinical and Laboratory Practice, pp. 128-139. London: Public Health Laboratory Service.

Yang, S. Y. \& Zhao, C. S. (1993). Review of 144 patients with brain abscess. Surg Neurol 39, 290-296. 